\title{
Cell-free chromatin particles released from dying cells inflict mitochondrial damage and ROS production in living cells
}

\author{
Bhabesh Kumar Tripathy ${ }^{\dagger}$, Kartikeya Avadhani ${ }^{\mp}$, Gorantla V Raghuram, \\ Kavita Pal, Naveen Kumar Khare, Relestina Lopes, Indraneel Mittra
}

Translational Research Laboratory

Advanced Centre for Treatment, Research and Education in Cancer

Tata Memorial Centre

Kharghar, Navi Mumbai - 410210, India and

Homi Bhabha National Institute, Anushakti Nagar, Mumbai -400094

\section{*}

Author for correspondence: Indraneel Mittra; imittra@actrec.gov.in

Ť These two investigators contributed equally to the work. 


\section{Graphical abstract}

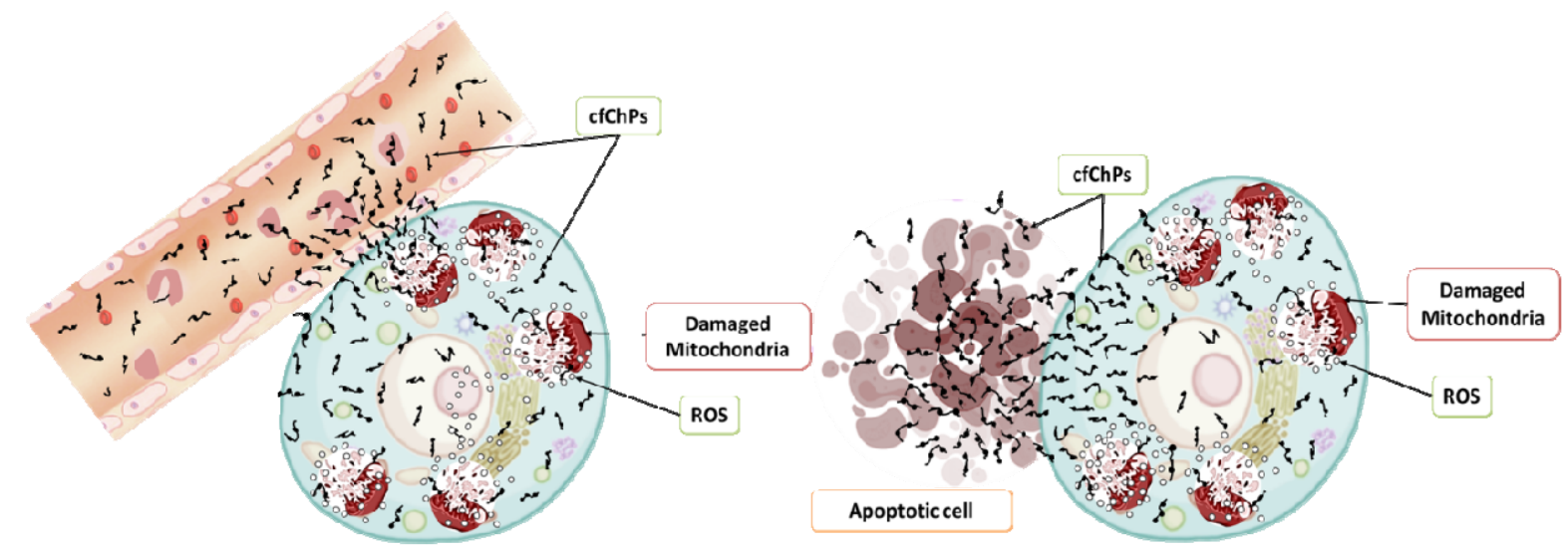

Legend: Cell-free chromatin particles (cfChPs) that circulate in blood, and those that are released locally from dying cells, can readily enter into healthy cells to damage their mitochondria leading to ROS production.

\section{Highlights}

1. Cell-free chromatin particles (cfChPs) are continuously released from dying cells

2. cfChPs can readily enter into living cells

3. The internalised cfChPs inflict physical damage to mitochondria

4. cfChPs induced mitochondrial damage results in ROS production and oxidative stress

5. cfChPs are novel triggers for ROS production with implications for health and disease 


\section{Abstract}

Several hundred billion to a trillion cells die in the body every day and release cell free chromatin particles (cfChPs) which enter into the circulation, or are released locally into extracellular compartments of the body. We have reported that cfChPs from the dying cells can readily enter into living cells and damage their DNA. To test the hypothesis that internalised cfChPs might also inflict mitochondrial damage, we treated NIH3T3 mouse fibroblast cells with cfChPs isolated from sera of healthy individuals (10ng), or co-cultured the cells with hypoxia induced dying NIH3T3 cells. Abundant cfChPs could be detected in the cytoplasm of the treated cells by $4 \mathrm{~h}$. The latter was associated with evidence of mitochondrial damage in the form of ultra-structural changes, increased mitochondrial mass, alterations in mitochondrial shape, upregulation of the mitochondrial outer membrane protein TOM20, and changes in mitochondrial membrane potential. We also detected increased fluorescence signals of $\gamma-\mathrm{H} 2 \mathrm{AX}$ and $\mathrm{p}$ ATM signifying double-strand breaks in mitochondrial DNA. There was marked increase in production of mitochondrial superoxide (ROS) as detected by MitoSOX Red, and activation of the intracellular antioxidant enzyme superoxide dismutase-1. Mitochondrial damage and ROS production could be inhibited by a cfChPs deactivating agent viz. anti-histone antibody complexed nanoparticles. Given that $1 \times 10^{9}-1 \times 10^{12}$ cells die in the body every day, we propose that cfChPs are major physiological triggers for mitochondrial damage and ROS production with an important bearing on human health and disease. Deactivation of cfChPs may provide a novel therapeutic approach to retard ageing and associated degenerative conditions that have been linked to oxidative stress. 
Key words: Oxygen radicals, free radicals, ROS, DNA damage, oxidative stress, apoptosis

\section{Introduction}

It is believed that the mitochondrial electron transport chain is the predominant source of intracellular ROS production during oxidative phosphorylation (1). Under normal physiological conditions, ROS levels are regulated by a balance between generation of ROS and their elimination by several antioxidant enzymes and non-enzymatic defence systems $(1,2)$. Oxidative stress can arise when there is excess production or inefficient elimination of ROS. Under conditions in which mitochondrial generation of ROS is in excess, these reactive oxygen species may lead to irreversible damage to mitochondrial proteins, membrane lipids and DNA, resulting in mitochondrial dysfunction and ultimately cell death (1-3). Chronic mitochondrial dysfunction is associated with ageing and several degenerative conditions such as diabetes, cardiovascular diseases, neurodegenerative disorders and cancer (4-8). In this article we provide evidence for a novel physiological agent in the form of cell-free chromatin particles (cfChPs) which promote ROS production by inflicting mitochondrial damage.

Several hundred billion to a trillion cells die in the body everyday $(9,10)$, and a proportion of cfChPs that are released from the dying cells enter into circulation (11). We have reported that circulating cfChPs, or those that are released locally from dying 
cells, can readily enter into healthy cells to induce double-strand DNA breaks, inflammation and apoptotic responses (12-14). Under electron microscopy, cfChPs isolated from human sera were found to be variable in size ranging from $\sim 10$ nanometres to $>200$ nanometres (12). We have shown that uptake of cfChPs and the ensuing DNA damage leads to severe genomic instability and chromosomal aberrations (15). We hypothesised that, in addition to genomic and chromosomal damage, the internalised cfChPs may also induce physical damage to mitochondria. We show in the present study that this is indeed the case. Treatment of NIH3T3 mouse fibroblast cells with cfChPs isolated from healthy individuals (10 $\mathrm{ng}$ equivalent of DNA) led to rapid uptake of cfChPs which accumulated in the cytoplasm within four hours. This was accompanied by evidence of severe mitochondrial damage in the form of: 1) ultrastructural changes in mitochondria detected by electron microscopy; 2) increased mitochondrial mass detected by staining with MitoTracker Green FM; 3) changes in mitochondrial shape detected by staining with MitoTracker Red CMXRos; upregulation of mitochondrial outer membrane protein TOM20 detected by immunofluorescence; 5) depolarization of mitochondrial membrane detected by fluorescent staining with JC-1;6) evidence of mitochondrial DNA damage detected by increased immuno-fluorescence signals of $\gamma-\mathrm{H} 2 \mathrm{AX}$ and $\mathrm{p}-\mathrm{ATM}$ signifying double-strand breaks. The above mitochondrial damage led to marked activation of ROS production detected as increased MitoSOX Red expression. The latter was accompanied by activation of the intracellular antioxidant enzyme superoxide dismutase-1, indicative of increased intracellular oxidative stress. We also undertook experiments in which culture media collected from hypoxia induced dying NIH3T3 cells were applied to live NIH3T3 cells. 
We found highly significant activation of ROS production in the treated cells; the latter could be inhibited by a cfChPs deactivating agent viz. anti-histone antibody complexed nanoparticles (CNPs), indicating that the ROS activating agents present in the culture medium were cfChPs that were released from the hypoxia induced dying NIH3T3 cells.

The above results suggest that cfChPs that circulate in blood, and those that are derived from dying cells, are natural physiological triggers for mitochondrial damage and ROS production. Given that $1 \times 10^{9}-1 \times 10^{12}$ cells die in the body every day, we propose that cfChPs are major physiological triggers for mitochondrial damage and ROS production. They may have an important bearing on human health and disease, and we propose that deactivation of cfChPs may have therapeutic potential.

\section{Materials and Methods}

\section{Reagents and antibodies}

Details of commercial sources and catalogue numbers of reagents and antibodies used in this study are given in supplementary table 1.

\section{Isolation of cfChPs from sera of healthy donors}

Isolation of cfChPs from sera of healthy individuals was performed according to a protocol described by us earlier (12). The concentration of cfChPs was depicted in terms of its DNA content as estimated by the PicoGreen quantitation assay.

\section{Fluorescent dual labelling of cfChPs}


cfChPs were fluorescently dually labelled in their DNA by Platinum Bright 550 (red) and in their histones with ATTO-488 (green) according to a protocol described by us earlier (12).

\section{Synthesis of pullulan-histone antibody nanoconjugates (CNPs)}

Pullulan-histone antibody nanoconjugates were synthesized according to the protocol described by us earlier (16).

\section{Cell culture}

NIH3T3 embryonic mouse fibroblast cells were obtained from the American Type Culture Collection (ATCC, USA). Cells were grown in Dulbecco's Modified Eagle's Medium (DMEM) (Gibco, Catalog No.12800-017) containing 10\% bovine calf serum (Cytiva HyClone, Catalog No. SH30073) and maintained at $37 \square^{\circ} \mathrm{C}$ in an atmosphere of $5 \% \mathrm{CO}_{2}$ and air. For all experiments, cells were seeded at a density of $1 \times 10^{5}$ (unless otherwise stated) on coverslips in $1.5 \mathrm{ml}$ DMEM and incubated overnight before conducting the experiments.

\section{Procedure for collecting culture media from hypoxia induced dying NIH3T3 cells}

A dual chamber system was used to generate culture medium containing cfChPs. NIH3T3 cells were seeded at a density of $2 \times 10^{5}$ on ThinCert ${ }^{\circledR}$ Cell Culture Inserts (pore size $400 \mathrm{~nm}$ ) containing $1.5 \mathrm{ml}$ of DMEM and placed on a six-well plate. Cells were incubated at $37^{\circ} \mathrm{C}$ for $24 \mathrm{~h}$. The plates with Thincert ${ }^{\circledR}$ Cell Culture Inserts were then transferred to a hypoxia chamber with $1 \% \mathrm{O}_{2}$ to induce hypoxic cell death with release of cfChPs. After 48h, the plates were removed from the hypoxia chamber and the Inserts were transferred to culture dishes containing $700 \mu$ of DMEM media and kept for 
$48 \mathrm{~h}$ at $37^{\circ} \mathrm{C}$ to allow cfChPs $<400 \mathrm{~nm}$ in size to seep into the medium in the culture dish below. A total of $4.6 \mathrm{ml}$ of medium was collected in the lower chamber. They were pooled and divided into aliquots and stored at $-80^{\circ} \mathrm{C}$. After 24 hours, two aliquots were thawed for use in the dose / volume response experiment. A dose / volume response experiment was performed in which increasing volumes of the culture medium was added to NIH3T3 cells and ROS levels were measured by MitoSOX Red staining. A dose of $50 \mu \mathrm{l}$ was found to be the most effective dose (Supplementary fig. 1). Once the optimal dose (volume) was ascertained, another aliquot was thawed for experiments using the cfChPs inhibitor viz. CNPs (please see below).

\section{Experiments with culture medium from hypoxia induced dying NIH3T3 cells with or without CNPs}

An aliquot $(1 \mathrm{ml})$ of collected culture media containing cfChPs was thawed and treated with CNPs $(25 \mu \mathrm{g} \mathrm{H} 4 \mathrm{lgG}$ in $125 \mu \mathrm{l})$ by incubating for $1 \mathrm{~h}$ at $25^{\circ} \mathrm{C}$. NIH3T3 cells were treated with culture medium with or without CNPs in a volume of $50 \mu \mathrm{l}$ (as determined from the dose response experiment described above). ROS levels were measured at 4 h using MitoSOX Red.

\section{Fluorescence and confocal microscopy}

Cells were imaged using Spectral Bio-Imaging System (Applied Spectral Imaging, Israel). Images were captured using a 40x air objective on the Spectral Bio-Imaging system. The images were captured with the same exposure time, for both treated and control cells set to ensure the same conditions for comparison, while avoiding saturation and photo bleaching. For confocal microscopy, images were acquired using a $63 x$ oil 
objective on Zeiss LSM 780 laser scanning microscope (Carl Zeiss, Germany) and Leica SP8 confocal imaging system (Leica Microsystems, Wetzlar, Germany).

\section{Assessment of mitochondrial damage by electron microscopy}

NIH3T3 cells were seeded at a density of $1 \times 10^{6}$ in $10 \mathrm{ml} \mathrm{DMEM}$, and when they had reached a density of $4 \times 10^{6}$, they were treated with cfChPs (10 ng/1.5 ml culture media) for $4 \mathrm{~h}$. Control and treated cells were fixed with $3 \%$ glutaraldehyde in $0.1 \mathrm{M}$ sodium cacodylate buffer $(\mathrm{pH} 7.2)$ for $2 \mathrm{~h}$ at $4^{\circ} \mathrm{C}$ followed by $1 \%$ osmium tetroxide in $0.1 \mathrm{M}$ sodium cacodylate buffer for $1 \mathrm{~h}$ at $4^{\circ} \mathrm{C}$ The samples were then dehydrated using alcohol at $4^{\circ} \mathrm{C}$ and embedded in araldite resin to make ultrathin sections that were mounted onto EM grids for imaging. Grids were then examined under a JEM1400-Plus transmission electron microscope (JEOL, Japan).

\section{Measurement of mitochondrial mass using MitoTracker Green}

After treatment with cfChPs (10 ng) for $4 \mathrm{~h}$, cells were incubated in $100 \mathrm{nM}$ MitoTracker Green diluted in $2 \mathrm{ml}$ of Hank's balanced salt solution (HBSS, $\mathrm{pH} 7.4$ ) for 15 minutes at $37^{\circ} \mathrm{C}$. The cells were then washed with warm HBSS, counterstained with Hoechst, mounted on glass slides and imaged using the Spectral Bio-Imaging System.

\section{Assessment of mitochondrial damage using MitoTracker Red}

Cells seeded on coverslips were treated with cfChPs (10 ng) for 4h. MitoTracker Red (100ng) was added to the cells followed by 15 minutes incubation at $37^{\circ} \mathrm{C}$. The cells were then washed thrice with PBS, fixed using 4\% para-formaldehyde (PFA), counterstained with Vecta-shield DAPI and mounted onto glass slides. Images were acquired on the LSM 780 platform. 


\section{Assessment of mitochondrial membrane protein TOM20}

Immuno-staining for TOM20 was performed $4 \mathrm{~h}$ after cfChPs treatment $(10 \mathrm{ng})$. The treated NIH3T3 cells were fixed with $4 \%$ PFA for 15 minutes at $37^{\circ} \mathrm{C}$ followed by permeabilization using $0.2 \%$ Triton $\mathrm{X}-100$ for 30 min and blocking with 3\% BSA for $1 \mathrm{~h}$. Cells were immuno-stained using anti-rabbit TOM20 primary antibody and incubated overnight at $4^{\circ} \mathrm{C}$. Cells were stained with secondary anti-rabbit FITC antibody followed by mounting onto slides with Vecta-shield DAPI. Images were acquired on the Leica confocal SP8 imaging system.

\section{Assessing mitochondrial membrane potential}

Cells treated with cfChPs (10 ng) for $4 \mathrm{~h}$ were stained with JC-1 in HBSS followed by 15 minutes incubation at $37^{\circ} \mathrm{C}$. The cells were washed with HBSS, counterstained with Hoechst, mounted on glass slides and cell-associated fluorescence was detected using the Spectral Bio-Imaging System.

\section{Assessment of $\gamma-\mathrm{H} 2 \mathrm{AX}$ and $\mathrm{p}-\mathrm{ATM}$ by immuno fluorescence}

$2 \times 10^{5}$ cells seeded on a coverslip were treated with $10 \mathrm{ng}$ of cfChPs for $4 \mathrm{~h}$. The cells were stained with the mitochondrial stain MitoTracker Red and processed for immunostaining for $\gamma-\mathrm{H} 2 \mathrm{AX}$ and $\mathrm{p}-\mathrm{ATM}$ using appropriate antibodies according to immunofluorescence protocol described above. HBSS was used for washes instead of PBST. The cells were counterstained with Vecta-shield DAPI and mounted on slides. Images were acquired using Spectral Bio-Imaging System and mean fluorescence intensity in the extra-nuclear regions was measured. 


\section{Assessment of mitochondrial ROS production}

Following treatment of NIH3T3 cells with cfChPs (10ng) for $4 \mathrm{~h}$, cells were stained with $0.5 \mu \mathrm{M}$ MitoSOX Red in $2 \mathrm{ml}$ of HBSS for 15 minutes at $37^{\circ} \mathrm{C}$, washed with warm buffer, counter stained with Hoechst, mounted on glass slides and cell-associated fluorescence was measured using the Spectral Bio-Imaging System.

\section{Estimation of superoxide dismutase expression}

Cells were treated with cfChPs (10 ng) for $4 \mathrm{~h}$ followed by fixing with $4 \%$ paraformaldehyde (PFA) for 15 minutes at $37^{\circ} \mathrm{C}$. Cells were then immuno-stained as described in the protocol above, using primary antibody against SOD-1 and appropriate secondary antibody. Cells were mounted with Vecta-shield DAPI, and images were acquired through the Spectral Bio-Imaging System.

\section{Quantification of fluorescence intensity}

Mean fluorescence intensity (MFI) of images was measured using ImageJ (W. Rasband, Bethesda, USA).

\section{Statistical analysis}

All data are presented as Mean $\square \pm \square$ Standard Error of Mean (SEM). Statistical analysis was performed using GraphPad Prism 5 (GraphPad Software, Inc., USA, Version 5.0). Data were compared using Student's $\square \mathrm{t}-\square$ test (two tailed, unpaired) and $p \square<\square 0.05$ was taken as the level of significance. 
bioRxiv preprint doi: https://doi.org/10.1101/2021.12.30.474529; this version posted December 30, 2021. The copyright holder for this preprint (which was not certified by peer review) is the author/funder, who has granted bioRxiv a license to display the preprint in perpetuity. It is made available under aCC-BY-NC-ND 4.0 International license.

\section{Human Subjects}

Institutional Ethics Committee (IEC) approval was obtained for collecting blood samples from healthy volunteers and their signed informed consent was obtained on consent forms approved by IEC. 


\section{Results}

\section{1. cfChPs are rapidly internalised by cells to localize in the cytoplasm}

cfChPs isolated from sera of healthy individuals were fluorescently dually labelled in their DNA with Platinum Bright 550 and in their histones with ATTO-488 and added to NIH3T3 cells (10 ng equivalent of DNA). Abundant fluorescent cfChPs were detected in the cytoplasm by $4 \mathrm{~h}$ (Fig 1). There was a near 100\% co-localization of red and green fluorescence signals confirming that the co-localized yellow fluorescent spots represented cfChPs. Localization of cfChPs in the cytoplasm suggested that they might interact with the cellular organelles such as mitochondria. Since maximum accumulation of dual labelled cfChPs was detected at $4 \mathrm{~h}$, all further analyses/experiments described below were conducted at $4 \mathrm{~h}$.

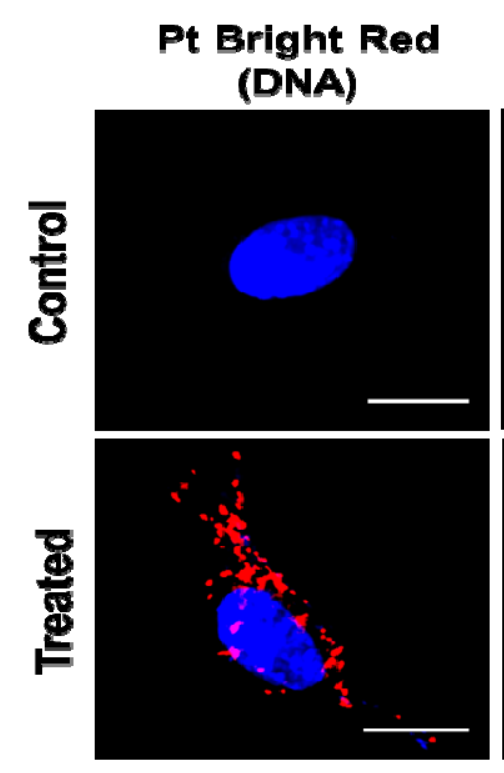

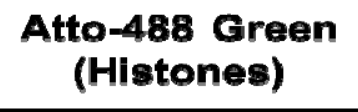
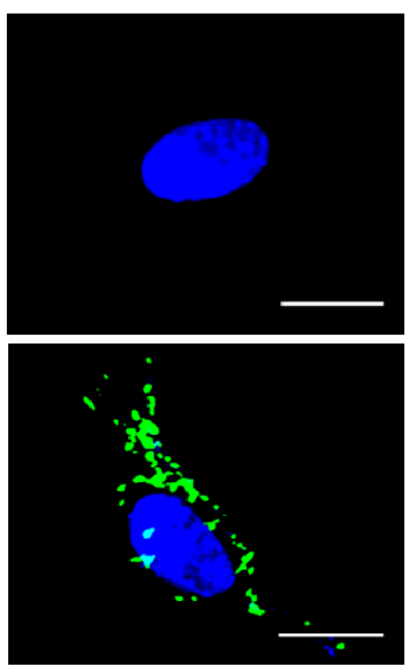

Merged

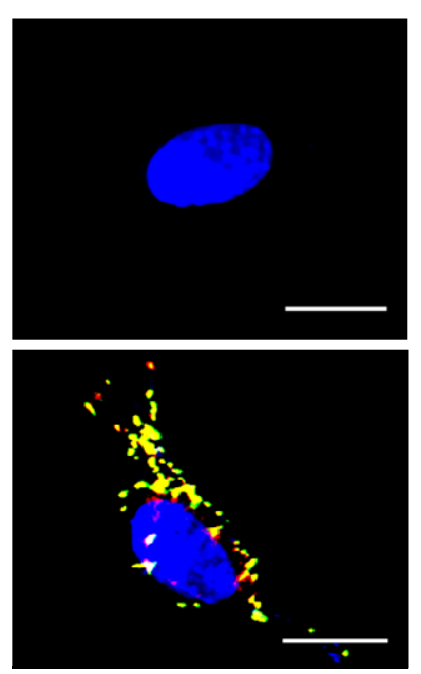

Figure 1: cfChPs are readily internalised by NIH3T3 cells. cfChPs (10ng) were fluorescently dually labelled in their DNA with Platinum Bright 550 (red) and in their histones with ATTO-488 (green) and added to NIH3T3 cells. Co-localized red and green signals generate yellow signals 
confirm that they represent cfChPs. Abundant cfChPs are seen in the cytoplasm at $4 \mathrm{~h}$. (Scale bar - $20 \mu \mathrm{m}$ )

\section{Internalised cfChPs induce mitochondrial damage}

We treated NIH3T3 mouse fibroblast cells with unlabelled cfChPs (10ng) isolated from healthy individuals for $4 \mathrm{~h}$ and examined the mitochondria of the treated cells by using six different methods.

2.1 Changes in mitochondrial ultra-structure: When examined under transmission electron microscopy (TEM), we observed that the control cells harboured healthy mitochondria which were elongated in shape, while most mitochondria in the cfChPs treated cells were rounded in appearance (Fig.2a). Rounded mitochondrial appearance has been reported to signify mitochondrial damage by other investigator (17). Results of quantification of elongated versus round mitochondria in control and treated cells are given in Fig.2b. The ratio of round to elongated mitochondria showed a three-fold increase in favour of round mitochondria in treated cells indicating increased mitochondrial damage. 
a

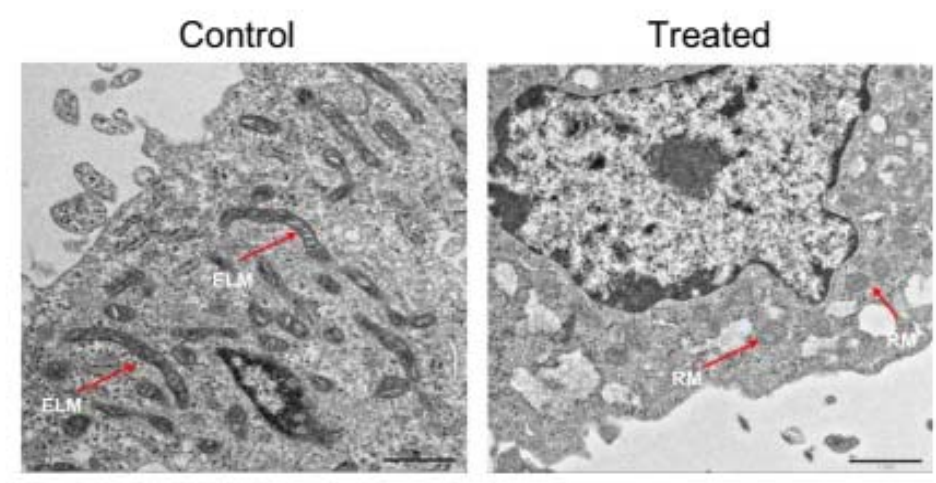

b
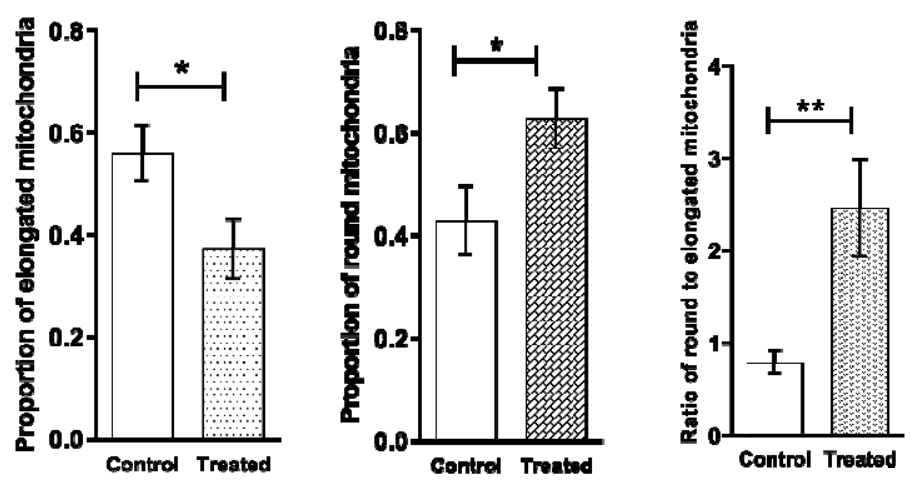

Figure 2: Ultra-structural changes in mitochondria following treatment of cells with cfChPs (10ng) at 4h. a. Representative TEM images of untreated and cfChPs treated cells. Control cells contain elongated mitochondria (red arrows), whereas cfChPs treated cells harboured mostly round shaped mitochondria (red arrows) (Scale bar - $1 \mu \mathrm{m}$ ). b. Quantification of elongated versus round mitochondria in control and cfChPs treated cells. The ratio of round to elongated mitochondria was significantly higher in cfChPs treated compared to control cells. Results represent mean \pm SEM values. Data were analysed using Student's $\square \mathrm{t}-\square$ test. ${ }^{*}=\mathrm{p}<0.05$, ** $=p<0.01$. ELM: Elongated Mitochondria, RM: Round Mitochondria.

2.2 Increase in mitochondrial mass: A cell up-regulates mitochondrial biogenesis in response to mitochondrial damage which results in increased mitochondrial mass (18). MitoTracker Green has been widely used to assess mitochondrial mass as it stains the mitochondria irrespective of its membrane potential (19). We observed a marked increase in MitoTracker Green fluorescence in cells treated with cfChPs, indicating that 
mitochondrial mass had increased as a result of damage inflicted by cfChPs treatment (Fig 3). Fluorescent measurements revealed a three-fold increase in mean fluorescence intensity (MFI) in treated cells when compared to controls (Fig 3).
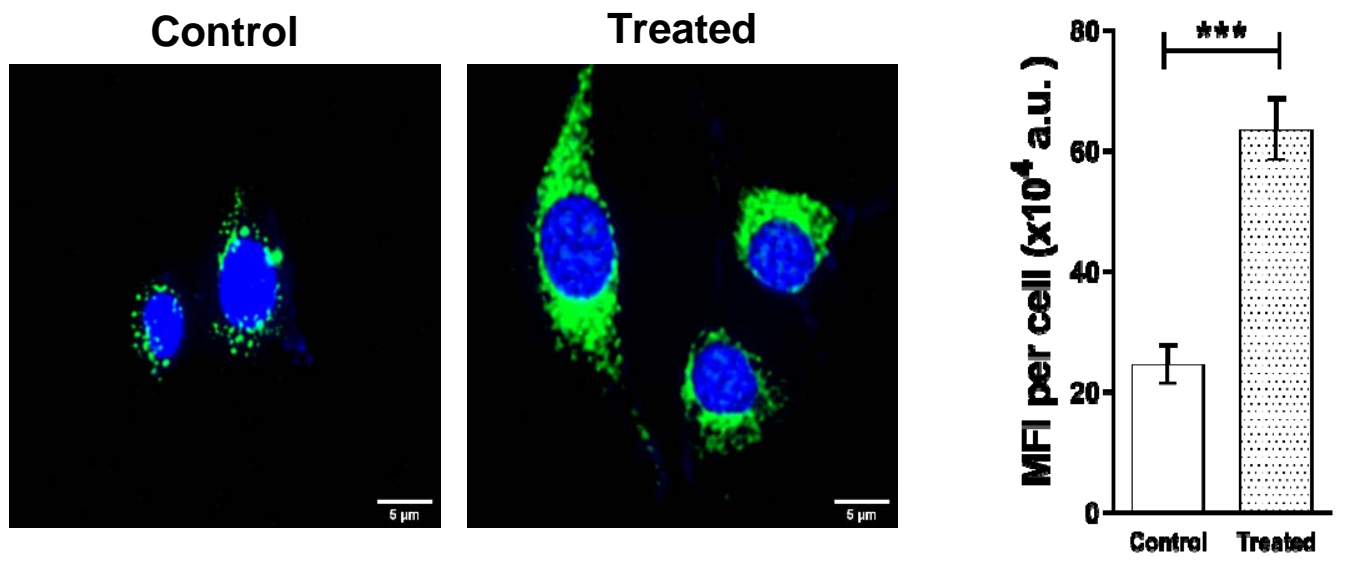

Figure 3: Treatment of NIH3T3 cells with cfChPs led to increase in mitochondrial mass. Representative images of untreated control and cfChPs treated cells (10ng) showing mitochondria labelled with MitoTracker Green at $4 \mathrm{~h}$. Cells treated with cfChPs exhibit higher fluorescence signals as compared to untreated cells (Scale Bar - $20 \mu \mathrm{m}$ ) (left hand panel). Quantitative analysis of MFI of MitoTracker green signals in untreated controls versus cfChPs treated cells. Cells treated with cfChPs show a significant increase in mitochondrial mass as indicated by a higher MFI per cell (right hand panel). Two hundred cells were analysed in each case and MFI per cell was calculated. Results represent mean \pm SEM values. Data were analysed using Student's $\square \mathrm{t}-\square$ test. ${ }^{* * *}=\mathrm{p}<0.001$.

2.3 Changes in mitochondrial shape: MitoTracker red detects changes in mitochondrial shape indicative of mitochondrial damage $(17,20)$. We stained the cfChPs treated (10ng) and control cells at $4 \mathrm{~h}$ with MitoTracker Red and examined them under confocal microscopy. Staining with MitoTracker Red revealed presence of a healthy network of mitochondria in control cells (Fig 4). The cfChPs treated cells, on the other hand, 
exhibited largely fragmented mitochondria appearing as diffused fluorescence signals which have been reported to represent mitochondrial fragmentation (17) (Fig 4).
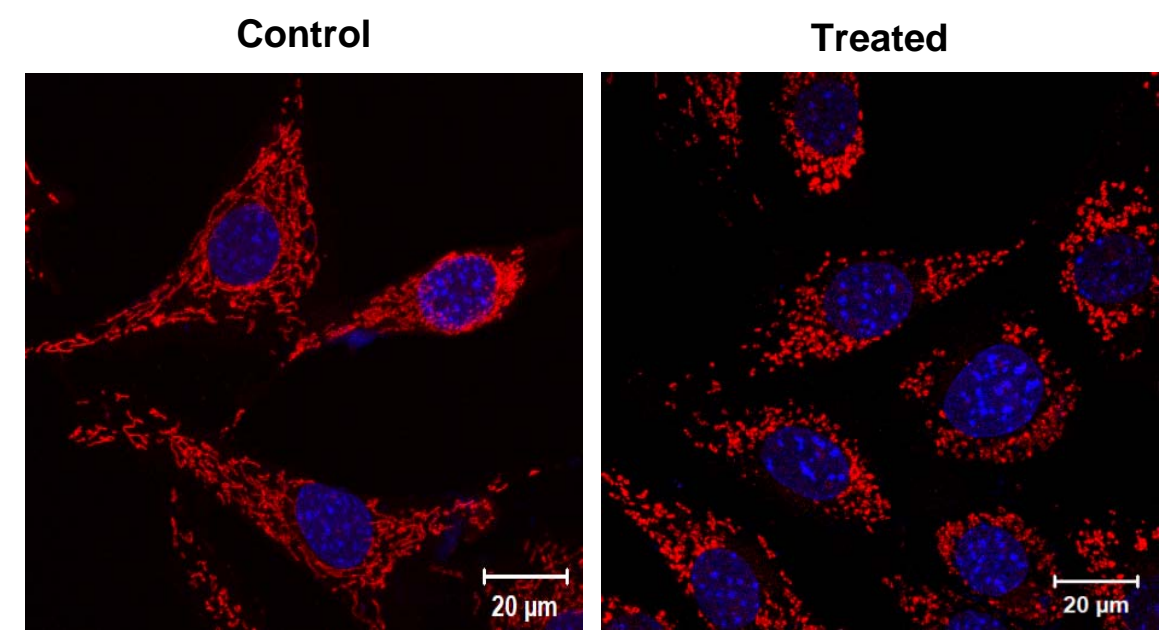

Figure 4: Representative confocal images showing treatment of NIH3T3 cells with cfChPs (10ng) induces mitochondrial damage in the form of morphological changes. Cells were stained with MitoTracker Red dye and analysed by confocal microscopy (4h). Control untreated cells exhibited healthy intact mitochondrial network, whereas cells treated with cfChPs exhibited fragmented mitochondria generating diffused fluorescence.

2.4 Upregulation of outer membrane protein TOM20: Translocase of the outer membrane 20 (TOM20) is an import receptor that belongs to the family of TOM proteins and allows movement of proteins across the mitochondrial outer membrane into the inner membrane space (21). Upregulation of TOM20 is a sign of dysfunctional mitochondria with increased biogenesis and excess import of proteins (22). We observed a marked increase in expression of TOM20 in cfChPs treated cells when compared to controls under confocal microscopy (Fig 5). Quantitative analysis 
expressed as MFI per cell showed a three-fold increase in TOM20 expression in cfChPs treated cells when compared to control untreated cells (Fig 5).

Control

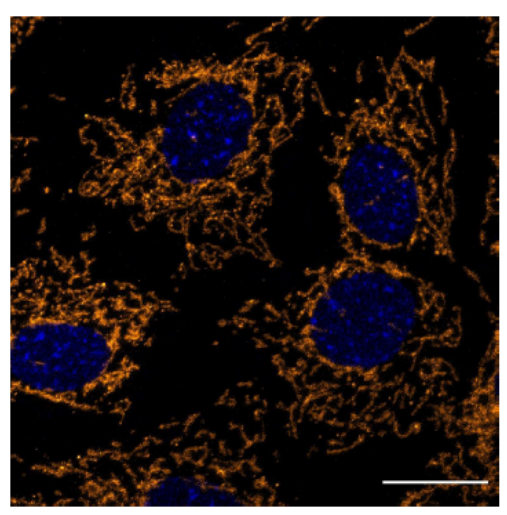

\section{Treated}

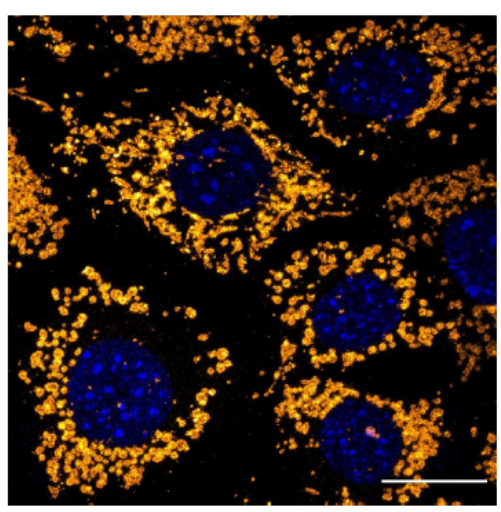

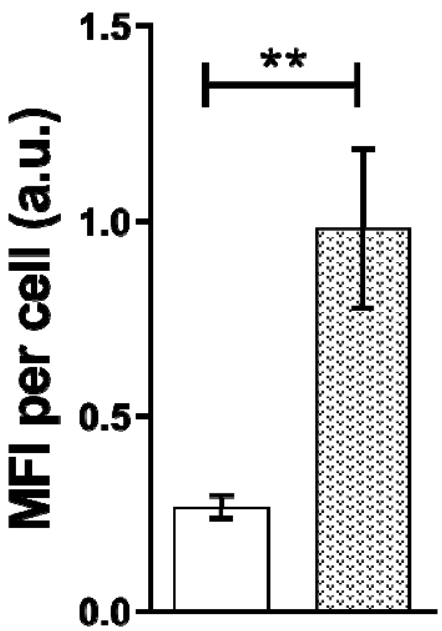

Control Treated

Figure 5: Treatment of $\mathrm{NIH} 3 \mathrm{~T} 3$ cells with cfChPs (10ng) induces mitochondrial damage and increased expression of TOM20 at 4h. Cells were immuno-stained with antibody against TOM20 followed by confocal microscopy. Representative images of untreated control and cfChPs treated cells showing TOM20 expression are given in the left hand panel. Expression of TOM20 was visibly higher in treated cells compared to untreated controls. (Scale Bar - $20 \mu \mathrm{m}$, Pseudo colour - Orange Hot). Quantitative analysis of TOM20 expression in control versus cfChPs treated cells exhibited a significantly higher MFI in treated cells (right hand panel). In each case, 25 cells were analysed and MFI per cell was calculated. Results represent mean \pm SEM values. Data were analysed using Student's $\square t-\square$ test. ${ }^{* *}=p<0.01$.

2.5 Altered mitochondrial membrane potential: Low mitochondrial membrane potential has been reported to be associated with mitochondrial damage (23). We investigated mitochondrial depolarization as an indicator of mitochondrial damage using JC-1 (5, 5', 6, 6'-tetrachloro-1, 1', 3, 3'-tetraethyl benzimidazolylcarbocyanine iodide) - a mitochondrial membrane fluorescent dye. JC-1 accumulates as aggregates in healthy 
mitochondria which are known to have a high membrane potential and emit red fluorescence. However, in dysfunctional mitochondria, JC-1 appears as monomers and emits green fluorescence since they have a relatively low membrane potential $(24,25)$. Representative images given in Fig 6 (left hand panel) show that while control cells have predominantly red signals, the cfChPs treated cells show abundance of green signals in addition to red signals. Quantitative analysis of the data revealed a highly significant increase in ratio of green to red fluorescence signals in cells treated with cfChPs (Fig 6 right hand panel). This indicated that cfChPs had caused damage to mitochondria of the treated cells, leading to decreased mitochondrial membrane potential.

Control

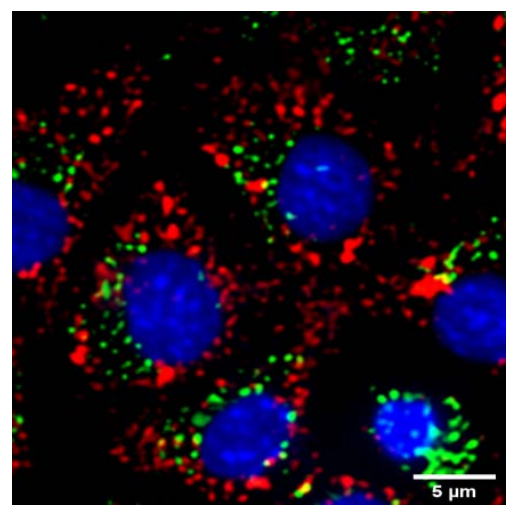

\section{Treated}

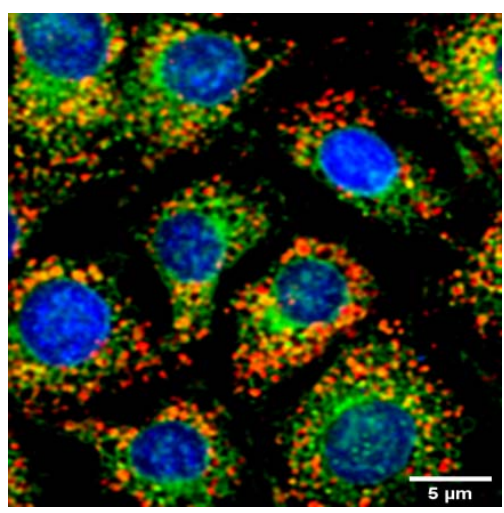

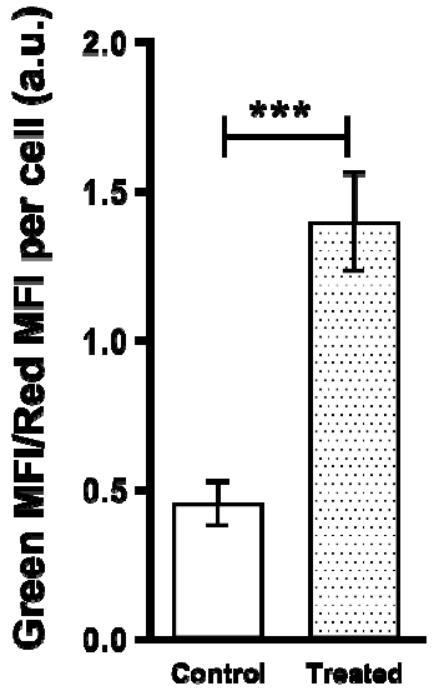

Figure 6: Treatment of NIH3T3 cells with cfChPs (10ng) induces mitochondrial damage in the form of alterations in mitochondrial membrane potential at $4 \mathrm{~h}$. The latter was detected by staining cells with JC-1 dye. Images in the left hand panel are representative images of untreated control and cfChPs treated cells. Control cells with healthy mitochondria exhibit higher red JC-1 fluorescence signals, whereas cells treated with cfChPs exhibit higher green fluorescence signals indicating loss of mitochondrial membrane potential. The right hand panel 
represents quantitative analysis of ratio of green to red fluorescence intensity in control and cfChPs treated cells. Cells treated with cfChPs show a three-fold higher ratio of green versus red fluorescence intensity. In each case, 200 cells were analysed and ratio of MFI of green to red signals per cell was calculated. Results represent mean \pm SEM values. Data were analysed using Student's $\square \mathrm{t}-\square$ test. ${ }^{* * *}=\mathrm{p}<0.001$. MFI: Mean Fluorescence Intensity, a.u.: arbitrary units.

\subsection{Increase in mitochondrial DNA damage:}

We have previously reported that cfChPs that circulate in blood are readily internalised by living cells whereupon they induce dsDNA breaks (12). We investigated whether the internalised cfChPs would also induce mitochondrial DNA damage. Treatment of cells with exogenous agents such as formaldehyde has been reported to lead to mitochondrial DNA damage in the form of activation of H2AX and 53BP1 (26). We first treated NIH3T3 cells with MitoTracker Red to selectively stain the mitochondria, followed by staining the cells with immunofluorescent antibodies to $\gamma-\mathrm{H} 2 \mathrm{AX}$ and $\mathrm{p}-\mathrm{ATM}$. We observed activation of both the markers of dsDNA breaks to be associated with mitochondria in the treated cells; the control cells exhibited low levels of these DNA damage markers. Quantitative analysis of fluorescence intensity was performed after excluding the nuclear signals. Three hundred fifty cells were analysed for both treated and control cells and MFI per cell was determined. We observed a highly significant increase in the levels of both $\gamma-\mathrm{H} 2 \mathrm{AX}$ and $\mathrm{p}-\mathrm{ATM}$ in the treated cells indicating that cfChPs that had entered into the cytoplasm had induced damage to mitochondrial DNA. 
a.
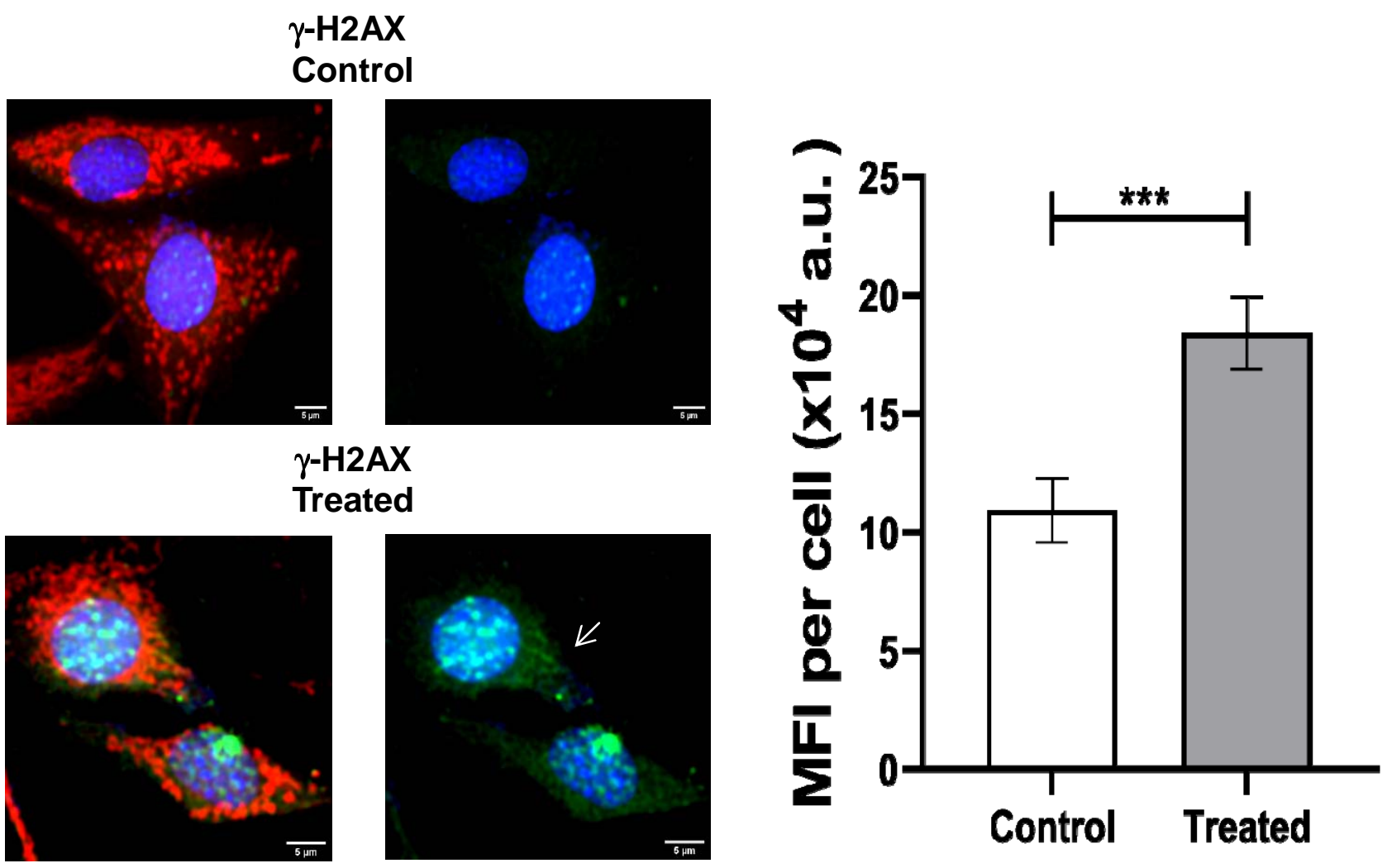

b.
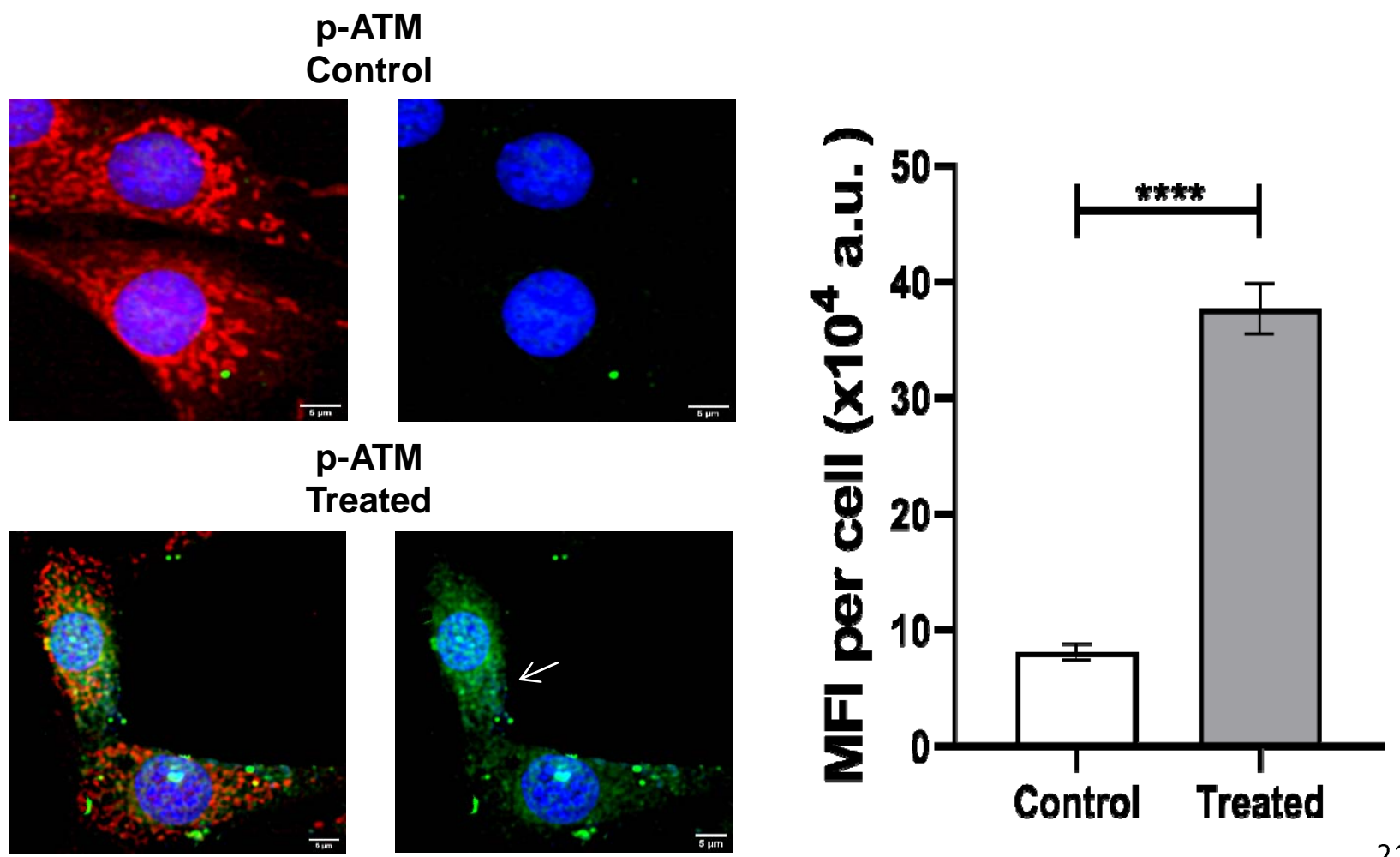
Figure 7: Treatment of NIH3T3 cells with cfChPs (10ng) induces mitochondrial DNA damage in the form of expression of $\gamma \mathrm{H} 2 \mathrm{AX}$ and $\mathrm{pATM}$ at $4 \mathrm{~h}$. a. $(\gamma \mathrm{H} 2 \mathrm{AX})$. Representative images of untreated control and cfChPs treated cells dually stained with MitoTracker red dye and antibody against $\gamma \mathrm{H} 2 \mathrm{AX}$ (green). Expression of $\gamma \mathrm{H} 2 \mathrm{AX}$ was visibly increased in the mitochondria of cfChPs treated cells as compared to control cells (Scale Bar - $5 \mu \mathrm{m}$ ) (left hand panel). Quantitative analysis of $\gamma \mathrm{H} 2 \mathrm{AX}$ expression in control versus cfChPs treated cells (right hand panel). Cells treated with cfChPs exhibited a significantly higher MFI for $\gamma \mathrm{H} 2 \mathrm{AX}$ as compared to untreated controls. b. (pATM). All experimental conditions were same as described above for $\gamma \mathrm{H} 2 \mathrm{AX}$. Cells treated with cfChPs exhibited a significantly higher MFI for pATM as compared to untreated controls. In all cases, 350 cells were analysed and MFI per cell was calculated. Results represent mean \pm SEM values. Data were analysed using Student's $\square \mathrm{t}-\square$ test. *** $=p<0.001,{ }^{* * * *}=p<0.0001$.

\section{3. cfChPs treatment triggers ROS production}

Superoxide radicals are one of the primary forms of ROS generated in the mitochondria (3). Their production in cells can be detected using MitoSOX Red, a triphenylphosphonium (TPP+)-linked DHE compound that is selectively oxidized by superoxide radicals and which emits red fluorescence (27). We investigated whether mitochondrial damage that we have described above might lead to increased ROS production. We treated NIH3T3 cells with cfChPs (10ng) followed by staining the cells with MitoSOX Red at $4 \mathrm{~h}$. We detected a marked increase in MitoSOX fluorescence indicating increased mitochondrial superoxide production (Fig 8, left hand panel). Quantitative analysis expressed in terms of MFI per cell revealed a highly significant increase in MitoSOX Red expression in cfChPs treated cells when compared to untreated controls (Fig 8, right hand panel). 

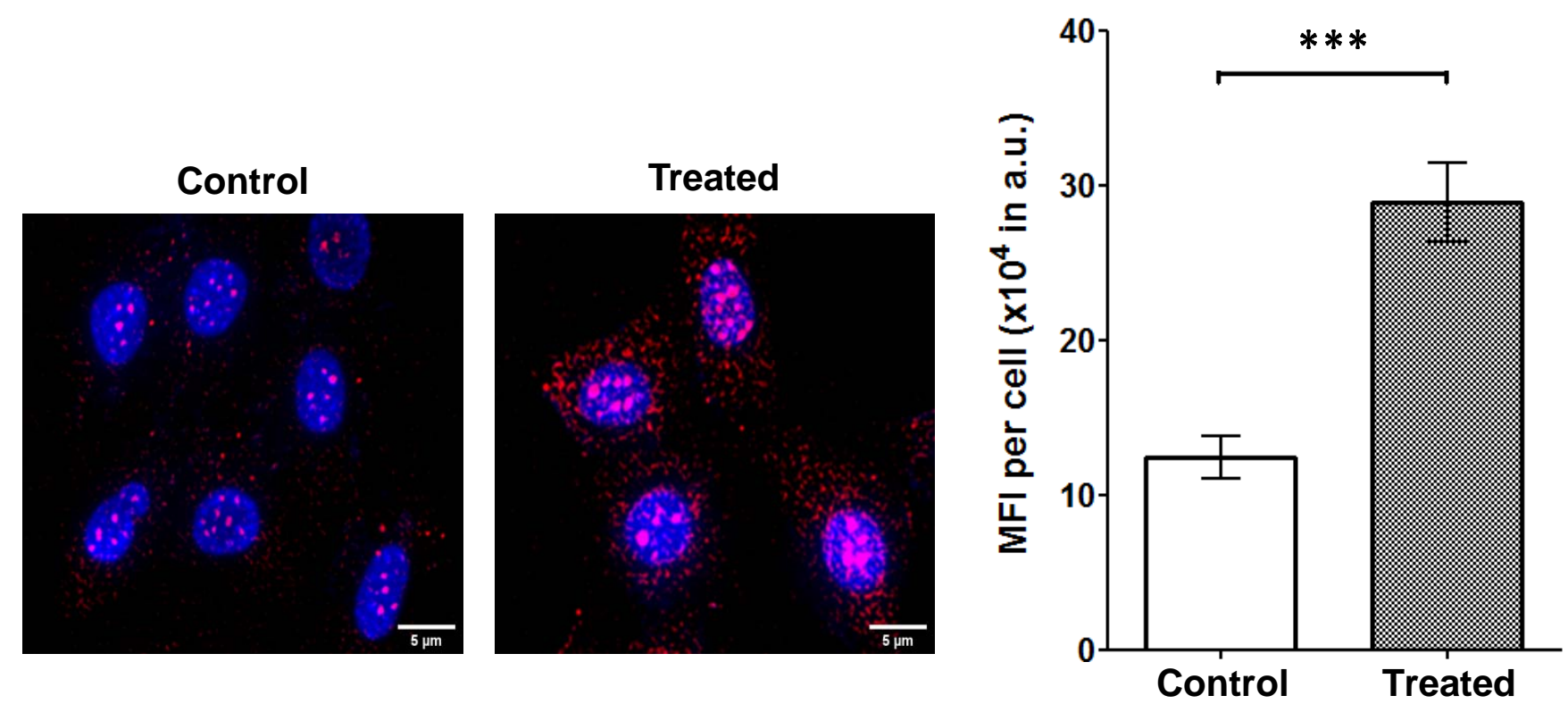

Figure 8: Treatment of NIH3T3 cells with cfChPs (10ng) activates ROS production at 4h. Representative images of control and cfChPs treated cells stained with MitoSOX Red. Treated cells show increase in MitoSOX Red fluorescence (Scale Bar - $5 \mu \mathrm{m}$ ) (left hand panel). Quantitative analysis of MitoSOX fluorescence in control versus cfChPs treated cells showing a highly significant increase in MFI for MitoSOX Red (right hand panel). In each case, 200 cells were analysed and MFI per cell was calculated. Data were analysed using Student's $\square \mathrm{t}-\square$ test. ${ }^{* * *}=p<0.001$.

\section{4. cfChPs treatment activates superoxide dismutase-1}

We next examined whether the ROS production following damage to mitochondria would lead to oxidative stress response in the form of activation of the antioxidant enzyme superoxide dismutase-1 (SOD-1) (28). cfChPs treatment led to marked upregulation of SOD-1. Representative image of SOD-1 expression given in Fig. 9 
shows higher fluorescence in cells treated with cfChPs when compared to untreated controls. Quantitative analysis expressed in terms of MFI per cell revealed a three-fold increase in SOD-1 expression in cfChPs treated cells when compared to untreated controls.
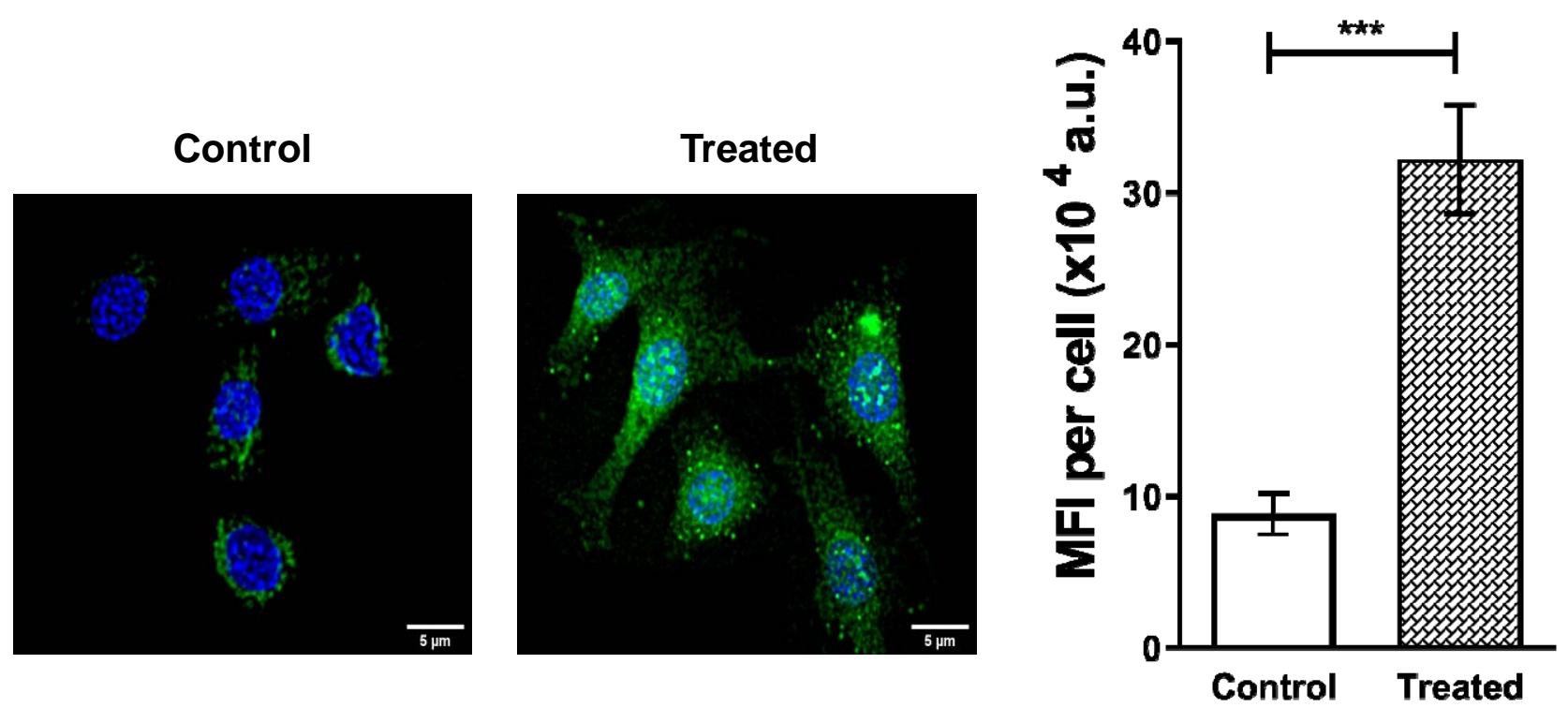

Figure 9: Treatment of $\mathrm{NIH} 3 \mathrm{~T} 3$ cells with cfChPs (10ng) induces activation of superoxide dismutase at $4 \mathrm{~h}$. Representative confocal images of untreated control and cfChPs treated cells immuno-stained with antibody against superoxide dismutase-1 (SOD-1). Cells treated with cfChPs show increased expression of SOD-1 (Scale Bar - $5 \mu \mathrm{m}$ ) (left hand panel). Quantification of SOD-1 levels in treated and untreated cells (right hand panel). In each case, 200 cells were analysed and MFI per cell was calculated. Results represent mean \pm SEM values. Data were analysed using Student's $\square$ t- $\square$ test. ${ }^{* * *}=p<0.001$.

\section{6. cfChPs released from dying cells trigger ROS production in bystander living cells}

We next examined whether cfChPs released into the culture medium from hypoxia induced dying NIH3T3 cells would trigger ROS production in healthy NIH3T3 cells. The method for generation of cfChPs containing culture medium has been described in 
Material and Methods section. Culture medium containing cfChPs released from hypoxia induced dying NIH3T3 cells were collected and applied to live NIH3T3 cells. As a first step, we performed a dose response experiment wherein we added increasing volumes of cfChPs containing culture medium to NIH3T3 cells, followed by assay for MitoSOX Red expression as a marker of ROS production. Optimum ROS production was seen with a volume of $50 \mu$ of culture media (Supplementary Fig. 1). A typical dose response effect was not seen because treatment of cells with volumes beyond $50 \mu \mathrm{l}$ induced cellular damage and death which could be visually observed. In order to confirm that cfChPs in the culture medium were responsible for ROS production, we pre-treated the culture medium with the cfChPs-deactivating agent viz. anti-histone antibody complexed nanoparticles (CNPs). CNPs pre-treated culture medium (50 $\mu \mathrm{l})$ resulted in a significant reduction in MitoSOX Red expression compared to cells treated with culture medium without CNPs (Fig 10). These observations indicated that it were the cfChPs released from hypoxia induced dying cells into the culture medium which were responsible for increased ROS production in live cells.

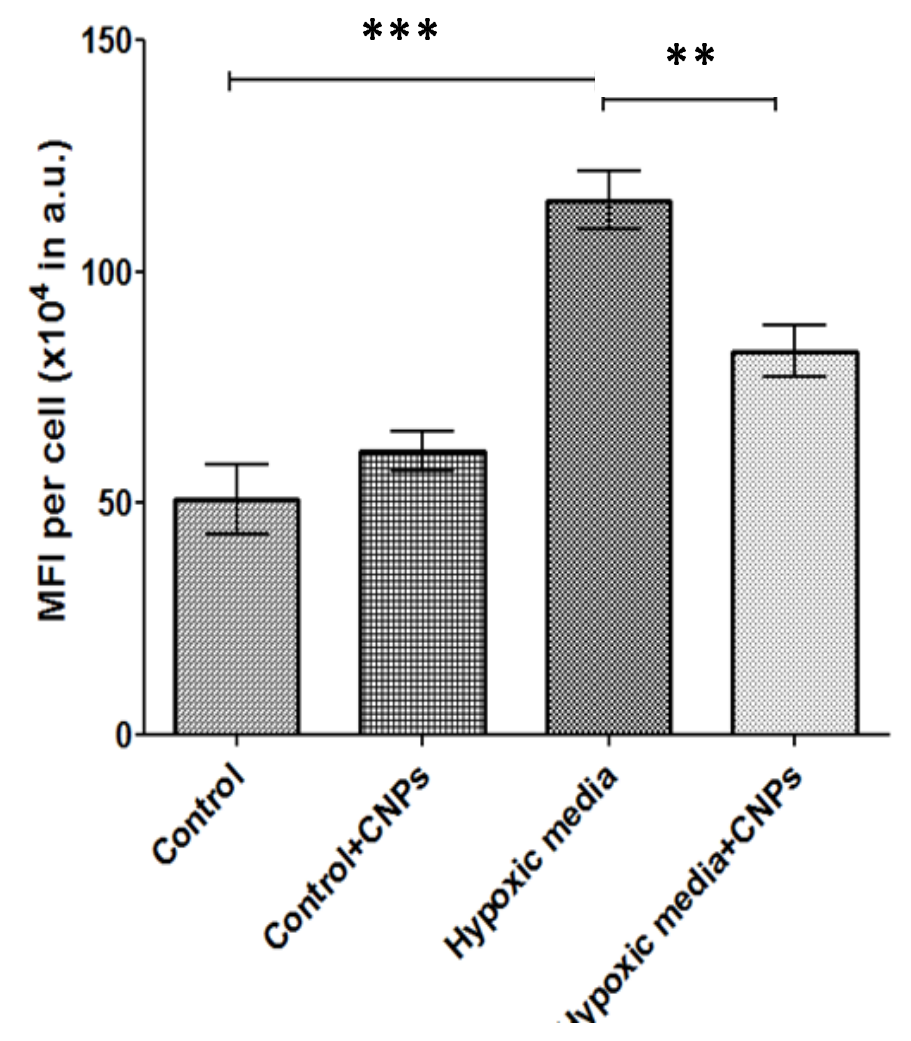


Figure 10: Activation of MitoSOX expression in NIH3T3 cells treated with $50 \mu$ of culture medium from hypoxia induced dying NIH3T3 cells, in presence or absence of CNPs (4h). Pretreatment of culture medium with CNPs significantly reduced MitoSOX expression. Two hundred cells were counted in each case. Results represent mean \pm SEM values. Data were analysed using Student's t-test. ${ }^{* *}=p<0.01,{ }^{* * *}=p<0.001$. 


\section{Discussion and conclusion}

We have shown in this article that treatment of NIH3T3 mouse fibroblast cells with cfChPs isolated from sera of healthy individuals, or co-culturing them with hypoxia induced dying NIH3T3 cells, led to significant mitochondrial damage and ROS production. The cfChPs were readily internalised by NIH3T3 cells and were seen to have accumulated in the cytoplasm by four hours. The latter was accompanied by mitochondrial damage in the form of ultra-structural changes, increased mitochondrial mass, alterations in mitochondrial shape, upregulation of the mitochondrial outer membrane protein TOM20, and reduction in mitochondrial membrane potential. We also detected increased immuno-fluorescence signals of $\gamma$-H2AX and p-ATM signifying double-strand breaks in mitochondrial DNA. There was a marked increase in production of mitochondrial superoxide (ROS) as detected by MitoSOX Red and activation of the intracellular antioxidant enzyme superoxide dismutase-1. Taken together, we provide strong evidence that cfChPs are natural and physiological mitochondrial damaging agents which leads to ROS production. We also show that mitochondrial damage and ROS production can be significantly reduced by deactivating cfChPs with the use of CNPs.

We have earlier shown that cfChPs that circulate in the blood, or those that are released locally from dying cells, are readily internalised by living cells whereupon they induce DNA damage and inflammation (12-14). We had hypothesised that repeated assault on living cells by cfChPs occurring throughout life may be the underlying cause of ageing and related chronic disorders such as diabetes, cardiovascular diseases, neurodegenerative conditions and cancer (14). In this article we have provided evidence 
for an additional and new function of cfChPs, namely mitochondrial damage and ROS production. Since ROS induced oxidative stress is also involved in the conditions mention above, the present finding provides further support for our hypothesis that cfChPs are implicated in ageing, chronic diseases and cancer. Given that $1 \times 10^{9}-1 \mathrm{X}$ $10^{12}$ cells die in the body everyday $(9,10)$, it is not inconceivable that cfChPs induced mitochondrial damage and oxidative stress, together with the ability of cfChPs to induce genomic DNA damage and inflammation, have an important bearing on human health and disease. Our demonstration that deactivation of cfChPs can reduce ROS production has therapeutic potentials in retarding ageing and related chronic diseases. 


\section{Author contributions:}

B.K.T., K.A., G.V.R., K.P., N.K.K., R.L. conducted the experiment; B.K.T., K.A., G.V.R., I.M. conducted data analysis; G.V.R. supervised the experiments; B.K.T., K.A., G.V.R., I.M. wrote the paper; I.M. conceived the idea, procured funding, supervised the experiments, wrote the paper and approved the final manuscript.

\section{Funding:}

This study was supported by the Department of Atomic Energy, Government of India, through its grant CTCTMC to Tata Memorial Centre awarded to IM.

\section{Declaration of competing interests:}

The authors declare no competing interests.

\section{Acknowledgement:}

The authors thank Dr. Snehal Shabrish for preparing the graphical abstract and Mr. Ashish Pawar for his help in preparing manuscript. 


\section{References}

1. M. P. Murphy, How mitochondria produce reactive oxygen species. Biochem. J. 417 (2009) 1-13. https://doi.org/10.1042/BJ20081386

2. E. Birben, U. M. Sahiner, C. Sackesen, S. Erzurum \& O. Kalayci, Oxidative Stress and Antioxidant Defense. World Allergy Organ. J. 5 (2012) 9-19. https://doi.org/10.1097/WOX.0b013e3182439613

3. B. Halliwell \& J. M. C. Gutteridge, Free Radicals in Biology and Medicine. Oxford University Press. 2015. doi:10.1093/acprof:oso/9780198717478.001.0001

4. H. Cui, Y. Kong \& H. Zhang, Oxidative Stress, Mitochondrial Dysfunction, and Aging. J. Signal Transduct. 2012 (2012) 1-13. doi:10.1155/2012/646354

5. M. L. Boland, A. H. Chourasia \& K. F. Macleod, Mitochondrial Dysfunction in Cancer. Front. Oncol. 3 (2013) 292. https://doi.org/10.3389/fonc.2013.00292

6. R. Parish \& K. F. Petersen, Mitochondrial dysfunction and type 2 diabetes. Curr. Diab. Rep. 5 (2005) 177-183. https://www.science.org/doi/full/10.1126/science.1104343

7. S. W. Ballinger, Mitochondrial dysfunction in cardiovascular disease. Free Radic. Biol. Med. 38 (2005) 1278-1295. https://doi.org/10.1016/j.freeradbiomed.2005.02.014

8. K. Itoh, K. Nakamura, M. lijima \& H. Sesaki, Mitochondrial dynamics in neurodegeneration. Trends Cell Biol. 23 (2013) 64-71. https://doi.org/10.1016/j.tcb.2012.10.006

9. T. M. Fliedner, D. Graessle, C. Paulsen \& K. Reimers, Structure and function of bone marrow hemopoiesis: Mechanisms of response to ionizing radiation exposure. Cancer Biotherapy and Radiopharmaceuticals. 17 (2002) 405-426. https://doi.org/10.1089/108497802760363204

10. R. Sender \& R. Milo, The distribution of cellular turnover in the human body. Nat. Med. 27 (2021) 45-48. https://doi.org/10.1038/s41591-020-01182-9

11.S. Holdenrieder \& P. Stieber, Clinical use of circulating nucleosomes. Crit. Rev. Clin. Lab. Sci. 46 (2009) 1-24. https://doi.org/10.1080/10408360802485875 12. I. Mittra, N. K. Khare, G. V. Raghuram, R. Chaubal, F. Khambatti, D. Gupta, ... \& A. Dutt, Circulating nucleic acids damage DNA of healthy cells by integrating into 
their genomes. Journal of biosciences. 40(1) (2015) 91-111.

https://doi.org/10.1007/s12038-015-9508-6

13. I. Mittra, U. Samant, S. Sharma, G. V. Raghuram, T. Saha, P. Tidke, ... \& A. Dutt, Cell-free chromatin from dying cancer cells integrate into genomes of bystander healthy cells to induce DNA damage and inflammation. Cell death discovery, 3(1) (2017) 1-14. https://doi.org/10.1038/cddiscovery.2017.15

14. G. V. Raghuram, S. Chaudhary, S. Johari \& I. Mittra, Illegitimate and repeated genomic integration of cell-free chromatin in the aetiology of somatic mosaicism, ageing, chronic diseases and cancer. Genes. 10 (2019) 407. https://doi.org/10.3390/genes10060407

15. S. Kirolikar, P. Prasannan, G. V. Raghuram, N. Pancholi, T. Saha, P. Tidke, ... \& I. Mittra, Prevention of radiation-induced bystander effects by agents that inactivate cell-free chromatin released from irradiated dying cells. Cell death \& disease. 9(12) (2018) 1-16. https://doi.org/10.1038/s41419-018-1181-X

16. M. R. Rekha, K. Pal, P. Bala, M. Shetty, I. Mittra, G. S. Bhuvaneshwar, \& C. P. Sharma, Pullulan-histone antibody nanoconjugates for the removal of chromatin fragments from systemic circulation. Biomaterials. 34(27) (2013) 6328-6338. https://doi.org/10.1016/j.biomaterials.2013.05.019

17.D. B. Zorov, I. A. Vorobjev, V. A. Popkov, V. A. Babenko, L. D. Zorova, I. B. Pevzner, ... \& E. Y. Plotnikov, Lessons from the discovery of mitochondrial fragmentation (fission): a review and update. Cells. 8(2) (2019) 175. https://doi.org/10.3390/cells8020175

18. N. Apostolova, L. J. Gomez-Sucerquia, A. Moran, A. Alvarez, , A. Blas-Garcia, \& J. V. Esplugues, Enhanced oxidative stress and increased mitochondrial mass during efavirenz-induced apoptosis in human hepatic cells. British journal of pharmacology. 160(8) (2010) 2069-2084. https://doi.org/10.1111/j.14765381.2010.00866.x

19. L. F. Marques-Santos, J. G. P. Oliveira, R. C. Maia \& V. M. Rumjanek, Mitotracker Green Is a P-Glycoprotein Substrate. Biosci. Rep. 23 (2003) 199_ 212. https://doi.org/10.1023/B:BIRE.0000007693.33521.18 
20. I. Samudio, M. Konopleva, N. Hail Jr, Y. X. Shi, T. McQueen, T. Hsu, R. Evans, T. Honda, G. W. Gribble, M. Sporn, H. F. Gilbert, S. Safe, M. Andreeff, 2-Cyano3,12-dioxooleana-1,9-dien-28-imidazolide (CDDO-Im) directly targets mitochondrial glutathione to induce apoptosis in pancreatic cancer. J Biol Chem. 280(43) (2005) 36273-82. doi: 10.1074/jbc.M507518200.

21. J. Dudek, P. Rehling \& M. van der Laan, Mitochondrial protein import: Common principles and physiological networks. Biochim. Biophys. Acta - Mol. Cell Res. 1833 (2013) 274-285. https://doi.org/10.1016/j.bbamcr.2012.05.028

22. S. Franco-Iborra, T. Cuadros, A. Parent, J. Romero-Gimenez, M. Vila, \& C. Perier, Defective mitochondrial protein import contributes to complex l-induced mitochondrial dysfunction and neurodegeneration in Parkinson's disease. Cell death \& disease. 9(11) (2018) 1-17. https://doi.org/10.1038/s41419-018-1154-0

23. V. A. Popkov, E. Y. Plotnikov, K. G. Lyamzaev, D. N. Silachev, L. D. Zorova, I. B. Pevzner, ... \& D. B. Zorov, Mitodiversity. Biochemistry (Moscow). 80(5) (2015) 532-541. https://doi.org/10.1134/S000629791505003X

24. F. Sivandzade, A. Bhalerao \& L. Cucullo, Analysis of the Mitochondrial Membrane Potential Using the Cationic JC-1 Dye as a Sensitive Fluorescent Probe. BIO-PROTOCOL 9 (2019) e3128. DOI:10.21769/BioProtoc.3128 25. S. T. Smiley, M. Reers, C. Mottola-Hartshorn, M. Lin, A. Chen, T. W. Smith, ... \& L. B. Chen, Intracellular heterogeneity in mitochondrial membrane potentials revealed by a J-aggregate-forming lipophilic cation JC-1. Proceedings of the National Academy of Sciences. 88(9) (1991) 3671-3675.

https://doi.org/10.1073/pnas.88.9.3671

26. C. A. Nadalutti, D. F. Stefanick, M. L. Zhao, J. K. Horton, R. Prasad, A. M. Brooks, ... \& S. H. Wilson, Mitochondrial dysfunction and DNA damage accompany enhanced levels of formaldehyde in cultured primary human fibroblasts. Scientific reports. 10(1) (2020) 1-13. https://doi.org/10.1038/s41598020-61477-2

27. L. I. Johnson-Cadwell, M. B. Jekabsons, A. Wang, B. M. Polster, \& D. G. Nicholls, 'Mild Uncoupling' does not decrease mitochondrial superoxide levels in cultured cerebellar granule neurons but decreases spare respiratory capacity and 
increases toxicity to glutamate and oxidative stress. Journal of neurochemistry. 101(6) (2007) 1619-1631. https://doi.org/10.1111/j.1471-4159.2007.04516.x

28. C. K. Tsang, Y. Liu, J. Thomas, Y. Zhang \& X. F. S. Zheng, Superoxide dismutase 1 acts as a nuclear transcription factor to regulate oxidative stress resistance. Nat. Commun. 5 (2014) 3446. https://doi.org/10.1038/ncomms4446 